\title{
Transtorno do déficit de atenção e hiperatividade: possibilidades de atuação da Terapia Ocupacional em contextos educacionais
}

\section{Attention deficit hyperactivity disorder: possible performances of Occupational Therapy in educational contexts}

\author{
Carla Cilene Baptista da Silva ${ }^{1}$,Andrea Perosa Saigh Jurdi', \\ Fernando Vicente de Pontes ${ }^{1}$
}

\begin{abstract}
SILVA, C. C. B.; JURDI, A. P. S.; PONTES, F. V. Transtorno do déficit de atenção e hiperatividade: possibilidades de atuação da Terapia Ocupacional em contextos educacionais. Rev. Ter. Ocup. Univ. São Paulo, v. 23, n. 3, p. 283-8, set./dez. 2012.

RESUMO: O presente trabalho consiste em um relato de experiências vivenciadas ao longo de estágio de observação realizado no módulo: Terapia Ocupacional em Contextos Educacionais, ministrado no $3^{\circ}$ ano do curso de graduação da Universidade Federal de São Paulo (UNIFESP), entre os meses de setembro e novembro de 2010. Pretende-se aqui contribuir para reflexão sobre as possibilidades de atuação da terapia ocupacional relativas à educação inclusiva, em especial quanto às crianças com diagnóstico de Transtorno do Déficit de Atenção e Hiperatividade (TDAH). $\mathrm{O}$ presente artigo fundamenta-se nas discussões realizadas ao longo do semestre letivo em que ocorreram os estágios de observação e em estudos que afirmam que o TDAH advém de um processo de medicalização, que ocorre em escala crescente nas sociedades ocidentais e, na maior parte das vezes, representa a biologização dos conflitos sociais.
\end{abstract}

DESCRITORES: Terapia ocupacional; Transtorno do déficit de atenção com hiperatividade; Educação/recursos humanos; Educação especial/recursos humanos.

1. Universidade Federal de São Paulo - Campus Baixada Santista.

Endereço para Correspondência: Avenida Dona Ana Costa, 95. Vila Mathias - Santos, SP. CEP: 11060-001. E-mail: carlaci@gmail.com 


\section{Transtorno do Déficit de Atenção e Hiperatividade (TDAH)}

$\mathrm{D}$ e acordo com o Manual Diagnóstico e Estatístico de Transtornos Mentais - DSM IV TR (2002), o Transtorno do Déficit de Atenção e Hiperatividade consiste em um padrão persistente de desatenção e/ou hiperatividade, com maior intensidade e gravidade do que o encontrado em crianças de nível de desenvolvimento semelhante. Surge antes dos sete anos de idade e interfere em pelo menos duas áreas de atuação da criança, como sua casa, escola e grupo de amigos. Trata-se de um transtorno frequentemente subdiagnosticado pelo pediatra (PASTURA; MATTOS, 2004).

Alguns estudos (PASTURA; MATTOS, 2004; PASTURA et al., 2005; FONTANA et al., 2007; POSSA et al., 2005) afirmam que ocorrendo a suspeita clínica, é importante o encaminhamento para diagnóstico, uma vez que o tratamento farmacológico é o indicado para estes casos.

Em contrapartida, outros estudos discordam do diagnóstico e do tratamento medicamentoso proposto. Collares e Moysés (1994) afirmam que o TDAH advém de um processo de medicalização que ocorre em escala crescente nas sociedades ocidentais e, na maior parte das vezes, representa a pura biologização dos conflitos sociais. Ao longo da história do TDAH, o diagnóstico foi legitimado, popularizado, universalizado e vem se tornando alvo de polêmicas desde a década de 1990, quando passou a ser incluído nas listas de doenças mentais. Desde meados da década de 1960, o TDAH vem sendo estudado pela psiquiatria e neurologia, constituindo em um diagnóstico construído a partir das contingências morais, sociais, científicas e dos modelos identitários, que ele fortaleceu desde seu surgimento. Segundo Caliman (2008), no final da década de 1980 e durante a década de 1990, o mundo presenciou uma explosão publicitária sobre o diagnóstico de TDAH e a substância metilfenidato, que compõe o medicamento mais conhecido e utilizado no tratamento do transtorno.

No contexto educacional, ser reconhecido como um indivíduo com TDAH na época de surgimento do diagnóstico nos Estados Unidos tornava-se um direito civil vinculado à decisão judiciária, tendo em vista que as crianças com o transtorno tinham garantido o direito à educação especial e assistência financeira (CALIMAN, 2009).

As estatísticas americanas mostraram o alarmante percentual de crianças e adolescentes diagnosticados e sob medicalização. Esses números também demonstravam os custos médicos e sociais do TDAH, apontando que o transtorno deveria ser tratado como um fator de risco e uma ameaça para os ideais de segurança e produtividade individual e social do país. (CALIMAN, 2008).

Pela difusão do tema no campo da saúde, Collares e Moysés (1994) afirmam que novas áreas profissionais em sua prática clínica estão envolvidas nesse processo, substituindo o termo "medicalização" pelo termo "patologização", uma vez que o fenômeno se ampliou e faz parte da prática de diversos profissionais. A crescente importância dada ao diagnóstico do TDAH nos EUA foi considerada por alguns críticos como um acontecimento de âmbito local. Entretanto, atualmente o TDAH tem sido compreendido como um assunto de interesse global, que desconhece barreiras culturais e de classes sociais.

No Brasil não são poucos os dados sobre o diagnóstico do TDAH e a utilização do medicamento metilfenidato, o que provoca o debate sobre o alarmante processo de medicalização e patologização que as crianças, principalmente em idade escolar, estão sofrendo (CALIMAN, 2009).

Nesse contexto, a educação, assim como todas as áreas sociais, vêem sendo medicalizadas, enfatizando o fracasso escolar e o seu reverso, a aprendizagem, como objetos essenciais desse processo Os problemas de aprendizado aparecem como de responsabilidade do aluno, e algumas vezes relacionados ao contexto familiar, sendo raramente questionados os papéis da instituição escolar e da comunidade nesse processo, o que parece ir na contramão do que dita a atual política de educação inclusiva.

Assim, a constituição social e científica do TDAH parece ser composta por outras questões de caráter político, ético, econômico e moral que dialogam com as exigências da economia atual. O diagnóstico do TDAH surgiu e se desenvolveu em um contexto sócio econômico no qual o indivíduo necessita ser bem-sucedido, produtivo, consciente, racional e prudente. Neste sentido, não há limites para as exigências de atenção, e na busca pela sua maximização, de modo que todo indivíduo será um pouco desatento, o que implica em cada vez mais indivíduos serem diagnosticados com TDAH (CALIMAN, 2009).

$\mathrm{Na}$ experiência de estágio de observação, descrita no próximo tópico, a investigação realizada junto aos educadores sobre a história de vida das crianças acompanhadas, notou-se que em geral, as crianças com diagnóstico de TDAH possuiam um contexto familiar conturbado, que pode ser agravado diante de um diagnóstico relacionado às necessidades educacionais especiais.

Vendrúsculo e Matsukura (2007) desenvolveram um estudo com o objetivo de identificar fatores protetivos 
em crianças em situações sócio-econômicas diferentes e relacionar esses resultados ao desempenho escolar satisfatório. Como resultados, as autoras enfatizaram a importância do papel da família em proporcionar condições favoráveis ao desempenho escolar da criança.

Para as famílias, ter um filho com diagnóstico de TDAH torna-se uma experiência difícil e de sofrimento em razão da convivência com os comportamentos apresentados pela criança, das reclamações vindas da escola, do desconhecimento sobre o transtorno, do medo da medicação utilizada para o tratamento e da falta de apoio à família (BALBI et al., 2008).

Nos casos específicos de crianças com TDAH, sua permanência e manutenção em ambiente escolar dependem do apoio familiar, para ampliação de suas oportunidades de aprendizagem e garantia do desenvolvimento de habilidades acadêmicas e sociais (ROCHA; DEL-PRETTE, 2010).

\section{Estágio de Observação em Educação Inclusiva}

A Politica Nacional de Educação Especial na Perspectiva da Educação Inclusiva (BRASIL, 2008) define como seu público-alvo os alunos com deficiência, transtornos globais do desenvolvimento e altas habilidades/ superdotação, e outros casos, que implicam em transtornos funcionais específicos. Dentre os transtornos funcionais específicos estão: dislexia, disortografia, disgrafia, discalculia, transtorno do déficit de atenção e hiperatividade.

A Política determina também, dentre outros aspectos, que a escola regular, de qualquer nível ou modalidade de ensino, ao viabilizar a inclusão de alunos com necessidades educacionais especiais, deverá promover a organização de classes comuns e de serviços de apoio especializados. Tais serviços deverão ser realizados mediante a atuação de diferentes profissionais das áreas de Educação e da Saúde. Ressalta ainda a necessidade de uma rede de apoio intersetorial nas áreas de Saúde, Assistência Social e do Trabalho.

Cabe aqui destacar que no panorama atual da educação inclusiva, essa proposta de atenção encontra-se em processo de implementação. Lourenço e Cid (2010) afirmam que alguns municípios, apesar das dificuldades com infraestrutura, capacitação de professores e reformulação dos serviços, estão fazendo esforços em busca de uma educação de qualidade para todos, inclusive com a sistematização de serviços desde os anos iniciais da escolarização no sentido preventivo até para o atendimento mais eficiente aos alunos com necessidades educacionais especiais, atendimento este realizado muitas vezes com a participação de equipes multidisciplinares.
No município em que foi desenvolvido o estágio de observação do módulo Terapia Ocupacional em Contextos Educacionais, há diferentes ações que visam à implementação da Política de Educação Especial na Perspectiva da Educação Inclusiva (BRASIL, 2008). Dentre elas, pode-se citar a contratação de professores auxiliares, perante diagnóstico da criança matriculada na educação infantil e no ensino fundamental, e o atendimento educacional especializado no contra turno das aulas regulares das crianças.

O módulo é realizado no sexto semestre letivo do curso de Terapia Ocupacional da UNIFESP, e conta com convênio com a prefeitura municipal de Santos para a realização das práticas de ensino. Tem por objetivos gerais: a) capacitar o estudante para compreender os fundamentos básicos de Educação Especial e o atual paradigma de Educação Inclusiva; b) identificar as diversas alterações do desenvolvimento infantil relacionadas à educação e aprendizagem; e c) identificar e compreender possíveis formas de intervenção da terapia ocupacional em diferentes contextos educacionais.

Inicialmente, as escolas municipais participantes são esclarecidas sobre as atividades práticas e os objetivos propostos no módulo. Antes de iniciar as práticas de estágio de observação, os estudantes de graduação realizam estudos teóricos sobre as atuais políticas de educação inclusiva e as recentes ações, no Brasil, da Terapia Ocupacional na área da Educação.

As atividades práticas de ensino do módulo consistem em acompanhar uma criança com necessidades educacionais especiais ou uma sala de aula por meio de observações no ambiente escolar; reuniões com professores e/ou outros profissionais da equipe educacional, investigações do histórico escolar e do diagnóstico da criança. Estas atividades foram desenvolvidas em cinco encontros realizados em escolas municipais de ensino básico e fundamental.

As atividades práticas também visam proporcionar aos estudantes a compreensão e análise do ambiente, da rotina e da dinâmica escolar, assim como as ações relativas às políticas públicas de educação sob uma perspectiva da integralidade das ações com a área da saúde.

No ano de 2010 a turma foi composta por 36 estudantes de terapia ocupacional. Eles foram organizados em duplas de trabalho e cada dupla acompanhou uma criança ou a rotina de uma sala de aula na rede municipal. As escolas foram determinadas pela Secretaria Municipal de Ensino, mediante ofícios de autorização e encaminhamento dos estudantes da UNIFESP a cada unidade. Cada dupla de estudante junto com a equipe pedagógica de cada escola 
definiu a criança ou a sala que foi foco das observações. Intercaladas com as práticas foram realizadas supervisões com as docentes responsáveis, para apresentação, discussão das observações e reflexão de possibilidades de intervenção. Ao todo ocorreram quatro supervisões, sendo duas contando com toda sala de aula, e duas nas quais a classe foi dividida em quatro grupos menores, o que permitiu o aprofundamento das discussões. Nas supervisões os estudantes foram orientados quanto à busca bibliográfica dos temas relativos às discussões e casos acompanhados nas observações para subsidiar as discussões e o trabalho final do módulo.

Ao final do semestre, os estudantes apresentaram um trabalho teórico prático cujo principal tópico visou a apresentação de propostas de intervenção da terapia ocupacional na escola. Estas propostas de intervenções podem envolver ações específicas para o caso observado e discutido com a equipe escolar, como por exemplo, adequação de mobiliário e realização de atividades cooperativas em pequenos grupos de crianças. Outras propostas podem envolver vários atores da escola, como oficinas lúdicas com a sala de aula da criança acompanhada ou oferecer meios de melhorar a comunicação entre os professores e as famílias.

Os estudantes apresentaram também aos profissionais das escolas, o trabalho teórico-prático por escrito sobre o estágio de observação, acompanhado de propostas de intervenção da terapia ocupacional. Entretanto, as propostas foram apenas apresentadas à comunidade escolar, pois com o final do semestre letivo não houve oportunidade de implementá-las e acompanhá-las.

No ano de 2010 houve um número crescente de demandas por parte dos educadores, em comparação aos anos anteriores, para o acompanhamento de casos diagnosticados com TDAH. Esse fato incitou as discussões em sala de aula e o interesse em apontar propostas exploratórias de intervenção da terapia ocupacional nas escolas tendo como pano de fundo a polêmica sobre o diagnóstico de TDAH, a medicalização e a possível patologização de situações e conflitos sociais.

Cabe esclarecer que na área da terapia ocupacional, foi realizado levantamento bibliográfico apenas em periódicos nacionais, e que nos mesmos não foram encontradas publicações sobre intervenções com TDAH.

\section{Possibilidades de Intervenção da Terapia Ocupacional}

Nessa perspectiva serão apresentados dois conjuntos de propostas de intervenção elaboradas e discutidas entre os estudantes do módulo Terapia Ocupacional em Contextos
Educacionais, no ano de 2010.

Um que visa envolver diferentes atores dos contextos educacionais, corroborando Rocha (2007), quando afirma que o objetivo da Terapia Ocupacional na educação é o fortalecimento do potencial de pensar e agir dos educandos, educadores e da família, visando colaborar com o processo de construção de possíveis soluções para as problemáticas trazidas a partir de cada grupo. $\mathrm{O}$ outro conjunto de propostas visa descrever, de modo exploratório, possibilidades de intervenção específicas aos casos de crianças diagnosticadas com TDAH.

Partindo do pressuposto de que a ação da terapia ocupacional na educação pode promover intervenções que potencializem a comunidade escolar na atenção aos alunos que necessitam de um atendimento educacional especializado, e com base em observações e discussões realizadas ao longo do estágio, produziram-se propostas de intervenção nesse contexto. Jurdi, Brunello e Honda (2004) afirmam que a parceria entre o campo de saúde e o da educação tem permitido proporcionar ações voltadas para as questões do cotidiano escolar. Através de trabalhos realizados nas escolas, é perceptível que as solicitações trazidas pelos profissionais da educação refletem a necessidade de se pensar práticas mais efetivas, que contemplem as atividades do cotidiano escolar e as relações que se estabelecem no mesmo.

As observações realizadas mostraram que os alunos com diagnóstico de TDAH apresentavam dificuldades para se manterem em sala de aula e baixo nível de atenção e concentração nas atividades propostas pela professora. Em muitos casos, essas crianças tumultuavam a rotina das salas dificultando a ordem estabelecida pela professora e, consequentemente, sofriam com o preconceito dos colegas de sala.

As observações da rotina escolar e do contexto da escola também permitiram conhecer as relações entre alunos, aluno-professor e escola-família. Considerando as crianças com diagnóstico de TDAH, a relação família-escola pareceu comprometida e muito frágil, além de dificuldades comuns dos professores em relação à forma dessas crianças aprenderem.

Com base nas práticas de estágio de observação e nas discussões em aula, foram propostas algumas intervenções que o terapeuta ocupacional pode realizar no contexto escolar:

- Junto aos professores: é importante que o terapeuta ocupacional possa apoiar o professor, informando-o sobre os conceitos básicos do TDAH e as consequências no aprendizado e em sala de aula. O terapeuta 
ocupacional tem elementos importantes no processo de construção das atividades que podem auxiliar o professor a reorganizar sua rotina escolar e o acesso das crianças ao conhecimento. Essa parceria entre professor e terapeuta pode propiciar a reflexão sobre as razões pela qual esse aluno está com dificuldade, suas características e possibilidades de aprendizado. Terapeuta e professor poderão construir um conhecimento comum a respeito do aluno.

Como o conhecimento não pode ficar restrito a um único professor é importante que as ações se voltem para a comunidade escolar. Para isso é importante participar de reuniões com o grupo de professores para problematizar e trazer à tona as experiências com os alunos que necessitam de mais atenção. Sugere-se como estratégia trabalhar com textos, filmes e imagens a respeito do processo de inclusão e temas atuais acerca desse processo. Ao final dessa atividade, o material obtido poderá ser organizado para exposição em pontos estratégicos da escola, onde os familiares e a comunidade possam ter contato e sejam sensibilizados pelo assunto. Cabe ressaltar que, diante da demanda de educação continuada relatada pelos professores, podem ser realizadas reuniões mensais sobre o desenvolvimento infantil, recursos educacionais (atividades e materiais alternativos na educação), inclusão escolar e direitos humanos. Considerando-se as necessidades específicas de cada criança, podem ser estabelecidas junto dos professores, estratégias alternativas para transmissão do conteúdo abordado em sala de aula. Poderão ser utilizadas atividades como o teatro, filmes, exposições, passeios fora da escola e até mesmo a música como forma de ensino e aprendizagem.

- Junto aos alunos: trabalhar as questões sobre as diferenças no ambiente escolar se faz necessário. Uma proposta é oferecer um espaço de uma tarde semanal para realizar brincadeiras dirigidas com os alunos de cada ano da escola. Podem ser utilizadas técnicas de pintura, jogos teatrais, jogos cooperativos, contação de histórias e outras atividades de interesse das crianças, com o objetivo de despertar um espaço lúdico na escola, com valorização da criatividade, experimentação, convivência e criação de vínculos.

- Junto á comunidade escolar: a família deve ter atenção especial. Pela fragilidade de vínculos entre as famílias e escola, o terapeuta ocupacional pode propor oficinas de atividades que ofereçam um espaço de interlocução entre escola e família. Os pais precisam de um espaço de acolhimento e apoio, ao mesmo tempo em que precisam conhecer melhor a respeito das dificuldades de seu filho. Nesses grupos de familiares seriam realizadas atividades, conversas e troca de experiências, com o objetivo de identificar como a família compreende o diagnóstico de TDAH, como está realmente acontecendo o processo de escolarização na visão da família, como compreendem a medicalização de seus filhos, além de oferecer apoio e escuta das dificuldades que se apresentam no cotidiano da criança e da família.

\section{CONSIDERAÇÕES FINAIS}

Considera-se relevante apontar que, como profissão surgida no campo da saúde, às vezes pode incorrer em práticas calcadas em uma perspectiva clínica de patologização de comportamentos e legitimação de diagnósticos. Nesse sentido, cabe ressaltar que constantes reflexões devem ser realizadas para que as práticas profissionais sejam condizentes com o contexto em que o terapeuta ocupacional está inserido, especialmente quando o alvo das intervenções são crianças diagnosticadas com TDAH no contexto escolar.

A escola pode se tornar um ambiente excludente e segregador, ao invés de ser um ambiente no qual a criança desenvolve habilidades que serão importantes no decorrer de toda sua vida. Nessa perspectiva, o terapeuta ocupacional pode apresentar uma visão crítica que considere os vários fatores relacionados aos contextos educacionais e sociais, como o ambiente escolar, a equipe educacional, a relação entre a escola e os familiares, o projeto pedagógico, a interface entre saúde e educação, entre outros.

Segundo Rocha et al. (2003), a meta a ser atingida pela Terapia Ocupacional nos contextos educacionais é o fortalecimento da potência de ação dos educadores e dos educandos, facilitando o surgimento de soluções para as problemáticas encontradas a partir do próprio grupo, utilizando-se como recurso diferentes atividades, adequadas as necessidades de cada realidade. Nesse sentido, é necessário criar soluções ao mesmo tempo particulares e coletivas, pois estar num contexto educacional reporta a estar em grupo, em diferentes espaços e atividades.

Por fim, vale ressaltar que a atuação do terapeuta ocupacional no processo de inclusão escolar, ainda é relativamente nova em nosso país. Diante disso, torna-se necessário a realização de novas práticas e de pesquisas, para que a atuação do terapeuta ocupacional seja consolidada, visando as crianças que se encontram em processo de inclusão escolar, para que sejam beneficiadas por novas práticas desses profissionais em conjunto com os profissionais da educação. 
SILVA, C. C. B.; JURDI, A. P. S.; PONTES, F. V. Attention deficit hyperactivity disorder: possible performances of Occupational Therapy in educational contexts. Rev. Ter. Ocup. Univ. São Paulo, v. 23 , n. 3, p. 283-288, set./dez. 2012.

\begin{abstract}
The present work is a report of experiences along of observation stage performed in the module: Occupational Therapy in Educational Contexts, instructed in 3rd. year of undergraduate course of the Universidade Federal de São Paulo (UNIFESP), between September and November 2010. The purpose is to contribute to the reflection about the possibilities of action from occupational therapy in regard to inclusive education, especially about children diagnosed with Attention Deficit and Hyperactivity Disorder (ADHD). This article is based on discussions along of the semester in which occurred stages of observation and studies that confirmed ADHD arises from a process of medicalization, which occurs on an increasing scale in Western societies and, in most times, represents the biologization social conflicts.
\end{abstract}

KEYWORDS: Occupational therapy; Attention deficit disorder with hyperactivity; Education/ manpower; Education, special/manpower.

\title{
REFERÊNCIAS
}

BALBI, C.; RIBEIRO, C. A.; BORBA, R. I. H.; OHARA, C. V. S.; PINTO, J. P. Compreendendo a vivência de ser mãe de uma criança com transtorno de déficit de atenção e hiperatividade. Rev. Soc. Bras. Enferm. Pediatr., v. 8, n. 2, p. 57-66. 2008.

BRASIL. Política Nacional de Educação Especial na Perspectiva da Educação Inclusiva. Brasília: Ministério da Educação e Cultura, Secretaria de Educação Especial, 2008.

CALIMAN, L. V. A constituição sócio-médica do "fato TDAH". Psicol. Soc., v. 21, n. 1, p. 135-144, 2009.

CALIMAN, L. V. O TDAH: entre as funções, disfunções e otimização da atenção. Psicol. Estud., v. 13, n. 3, p. 559-566, 2008.

COLLARES, C. A. L.; MOYSÉS, M. A. A. A transformação do espaço pedagógico em espaço clínico - a patologização da educação. Série Idéias, n. 23. São Paulo: FDE, 1994. p. 25-31.

FONTANA, R. S.; VASCONCELOS, M. M.; WERNER, J.; GÓES, F. V.; LIBERAL, E. F. Prevalência de TDAH em quatro escolas públicas brasileiras. Arq. Neuropsiquiat., v. 65, n. 1, p. 134-137. 2007.

JURDI, A. P. S.; BRUNELLO, M. I. B.; HONDA, M. Terapia Ocupacional e propostas de intervenção na rede pública de ensino. Rev. Ter. Ocup. Univ. São Paulo, v. 15, n. 1, p. 26-32. 2004.

LOURENÇO, G. F.; CID, M. F. B. Possibilidades de ação do Terapeuta Ocupacional na educação infantil: congruência com a proposta de educação inclusiva. Cad. Ter. Ocup. UFSCar, v. 18, n. 2, p. 169-179. 2010.

PASTURA, G.; MATTOS, P. Efeitos colaterais do metilfenidato. Rev. Psiq. Clin., v. 31, n. 2, p. 100-104. 2004.

PASTURA, G.; MATTOS, P.; ARAÚJO, A. P. Q. C. Desempenho escolar e transtorno do déficit de atenção e hiperatividade. Rev. Psiq. Clin., v. 32, n. 6, p. 324-329. 2005.

POSSA, M. A.; SPANEMBERG, L.; GUARDIOLA, A. Comorbidades do transtorno de déficit de atenção e hiperatividade em crianças escolares. Arq. Neuropsiquiatr., v. 63, n. 2-b, p.479483, 2005.

ROCHA, E. F. A terapia ocupacional e as ações na educação: aprofundando interfaces. Rev. Ter. Ocup. Univ. São Paulo, v. 18, n. 3, p. 122-127, 2007.

ROCHA, M. M.; DEL-PRETTE, Z. A. P. Habilidades sociais educativas para mães de crianças com TDAH e a inclusão escolar. Psicol. Argum., v. 28, n. 60, p.31-41, 2010.

ROCHA, E. F.; LUIZ, A. ZULIAN, M. A. R. Reflexões sobre as possíveis contribuições da terapia ocupacional nos processos de inclusão escolar. Rev. Ter. Ocup. Univ. São Paulo, v. 14, n. 2, p. 72-78, 2003.

VENDRÚSCULO, L. M.; MATSUKURA, T. M. Desempenho escolar satisfatório de crianças de diferentes realidades sócioeconômicas: identificando fatores protetivos. Cad. Ter. Ocup. UFSCar, v. 15, n. 1, p. 31-41. 2007. 